\title{
Special issue dedicated to W. A. J. (Wim) Luxemburg for the occasion of his 80th birthday
}

\section{Anton R. Schep}

(C) Springer Basel AG 2010

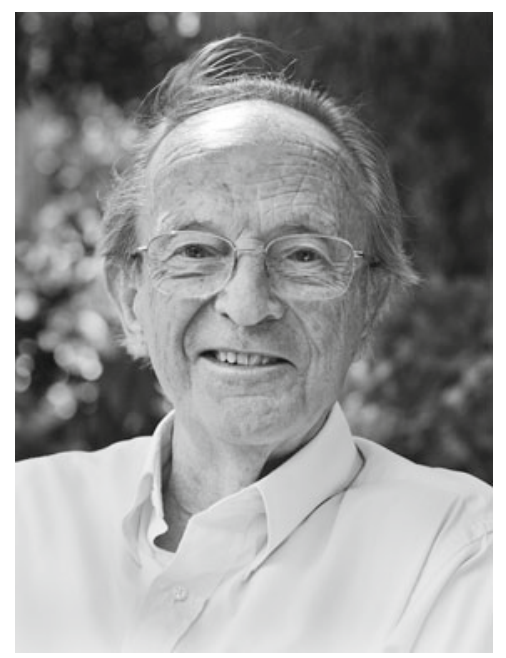

Fig. 1 Wim Luxemburg (This photograph was provided by Ron Luxemburg)

At the international conference Positivity VI, held in Escorial, Spain on July 20-24, 2009, the editorial board of Positivity met and decided to dedicate a special issue in honor of Wim Luxemburg's contributions to the area of positivity on the occasion of his 80th birthday. This issue of Positivity is the outcome of that decision. We will not try to summarize Wim Luxemburg's contributions here, as Peter Dodds' article in this issue will do this in much better way than I could do here. We would like to thank Ron Luxemburg for providing us with a current photograph of Wim (Fig. 1).

The editors of Positivity wish Professor Luxemburg many further creative years to come. 